\title{
PRIMERAS MANIFESTACIONES DE LA LENGUA DE NEGRO EN LA LITERATURA IBÉRICA: COMIENZO DE UN ESTEREOTIPO
}

\author{
Antonio Santos Morillo
}

\section{A) BREVE APUNTE HISTÓRICO}

Dos siglos después de haber terminado su propia reconquista, el reino de Portugal, motivado por diversos intereses ${ }^{1}$, inició su colonización africana. En 1415, los portugueses conquistaron Ceuta, ciudad que les serviría de base de operaciones para continuar su expansión hacia el sur: en 1434 pasaron el cabo Bojador, en 1445 alcanzaron la desembocadura del río Senegal y en 1475 llegaron a Benín. Al mismo tiempo que exploraban la costa africana, iban estableciendo factorías desde las que comerciaban con los gobernantes locales. Como consecuencia, el comercio de esclavos de la Edad Moderna comenzó a desarrollarse. Si bien es verdad que muchas de estas personas esclavizadas fueron a parar a Europa, hasta el siglo XVI la mayor parte iba destinada a las nuevas áreas coloniales europeas en las islas del Atlántico: Canarias, Madeira, Cabo Verde (Philips, 1990).

En los reinos de la Península Ibérica, la esclavitud había existido desde la antigüedad, pero fue a partir del siglo XV y gracias a la expansión portuguesa por la costa atlántica africana cuando comenzó una trata de esclavos negros a gran escala que se desenvolvería a lo largo de los tres siglos siguientes. Antes de 1479, fecha del Tratado de Alcáçovas por el que Castilla reconoció a Portugal los derechos y privilegios de tráfico, comercio, evangelización y conquista en el África negra, había abundantes esclavos negros en los reinos de Aragón y Castilla, pero fue a partir de la firma de dicho tratado cuando creció notablemente su número. El hecho de que los negros provinieran, casi en exclusiva, de los mercados portugueses tiene esencial importancia para entender el fenómeno del hablar guineo en las obras literarias o musicales españolas y en el posterior desarrollo de las lenguas criollas ya que, uno y otras, partieron en su formación de estructuras lingüísticas portuguesas (Granda, 1978: 216-233).

\section{B) BREVE Y CLÉRIGO}

La lengua de negro de las literaturas peninsulares tendrá abundantes elementos de la lengua franca de base portuguesa que los esclavos aprendían en las costas africanas. Los primeros testimonios aparecen en el Cancioneiro Geral de Garcia de Resende que, aunque fue publicado en 1516, recoge composiciones anteriores. Las que son motivo del presente

\footnotetext{
${ }^{1}$ Demográficos -la mano de obra escaseaba como consecuencia de las epidemias de peste negra sufridas en la segunda mitad del s. XIV-; económicos -hacía falta más oro para acuñar moneda y para comprar cereales, pues el que llegaba de las regiones auríferas del África occidental a través de las rutas de caravanas transaharianas cuyo monopolio estaba en manos de los musulmanes era insuficiente-; comerciales -había que ampliar los bancos de pesca, se necesitaban nuevas tierras para el cultivo de la caña de azúcar y la demanda de esclavos crecía-; y evangélicos -los negros vivían en pecado original pues no conocían la palabra de Dios-.
} 
trabajo, Breve de Fernão da Silveira y Clérigo de Anrique da Mota ${ }^{2}$, están escritas en el siglo XV. El texto de Fernão da Silveira fue compuesto, según Paul Teyssier (1959: 228), en 1455 con motivo de las bodas de la infanta Doña Juana de Portugal con Enrique IV de Castilla. El de Anrique da Mota es más difícil de datar. John M. Lipski (1999: 150) dice que probablemente se escribió en la primera década del siglo XV, pero debe de ser un error (por XVI) ya que el primer ejemplo de lengua de negro es el de Silveira y, además, Mota no había nacido aún. Osório Mateus (Mota, 1999: 13), basándose en la alusión que el clérigo protagonista hace al fallecimiento de un rey (v. 129), dice que en 1515 hacía veinte años de la última muerte de un monarca, Juan II, y que nadie, después de tantos años, utilizaría la expresión "no lloré tanto cuando el rey murió" como tópica; por consiguiente, la fecha de composición del texto estaría cerca de 1495: finales del XV o principios del XVI. En cualquier caso, según Peter E. Russell (1978: 383), las representaciones de danzas en las que participaban negros eran usuales en Portugal a mediados del siglo XV y, probablemente, el poema de Silveira estaría inmerso en una tradición literaria ya existente en Portugal.

El negro comienza a ser personaje literario con rasgos característicos propios (entre ellos, el habla) con el desarrollo de la actividad esclavista que los portugueses llevan a cabo a partir de finales del siglo XV. Frente a la buena consideración de que gozaban los etíopes en la literatura clásica, el hecho de que los negros se conviertan, con la trata moderna, en las principales y casi únicas personas sometidas a esclavitud (los moriscos empezarán a escasear y los indios, por una parte, no serán tan resistentes al sistema servil y, por otra, contarán con defensores de su condición libre), hará que se les considere como "bárbaros e inferiores, rasgo al que aluden la mayor parte de los textos literarios en los que aparecen" (Baranda, 1989: 313) y supondrá el pretexto para su desprecio y su ridiculización. Los textos aquí presentados inauguran este tópico literario que tendrá su continuación, en Portugal, con Gil Vicente y, en Castilla, con Rodrigo de Reinosa y otros escritores, sobre todo dramaturgos, del siglo XVI: Juan Pastor, Luis de Miranda, Jaime de Güete, Feliciano de Silva, Gaspar Gómez, Diego Sánchez de Badajoz y Lope de Rueda. Gil Vicente utiliza la lengua de negro en cuatro de sus obras: Fragua de amor (1524), Nao de amores (1527), Clérigo de Beira (1529/1530) y Floresta de engaños (1536), y Reinosa en unos diálogos que imitan el tono de primitiva farsa que posee, sobre todo, el texto de Anrique da Mota: "Comiençan unas coplas alos negros..." y "Otras suyas a los / mismos negros ..." (se le atribuye otra composición de este tipo: "Coplas de cómo una dama rue / ga a un negro que cante...", pero no es segura su autoría -Weber, 1963-). No sabemos exactamente cuándo escribió Reinosa estos diálogos; sin embargo, por las fechas que nos propone Frida Weber de Kurlat ${ }^{3}$ : entre 1516 y 1520 , y por las evidentes coincidencias formales y temáticas que tales textos guardan con la composición de Fernão da Silveira (Weber, 1963: 386-389) ${ }^{4}$, podemos deducir que son el autor santanderino, en España, y Vicente, en Portugal los que

\footnotetext{
${ }^{2}$ En el primer caso, utilizamos el título de Breve por ser una de las primeras palabras de un título demasiado largo; en el segundo, aprovechamos el título con que Osório Mateus se refiere a esta composición.

${ }^{3}$ Que rechaza por demasiado tempranas las de Cossío: entre los últimos años del siglo XV y los primeros del XVI.

${ }^{4}$ Peter E. Russell (1978: 382-383), sin embargo, duda de que haya habido influencia de la obra de Silveira en las composiciones de Reinosa. Centrándose en el primer poema de Reinosa, enumera las diferencias con respecto al portugués y le parece prueba insuficiente para una posible relación el hecho de que ambos empleen la lengua de negro y el arte mayor en sus composiciones. Piensa Russell que más bien estaríamos ante un caso de poligénesis.
} 
(partiendo de los mismos referentes) comienzan el camino de la sistematización del tópico. De hecho, los autores posteriores, tanto portugueses como españoles, variarán en poco los rasgos de la lengua de negro que encontramos en sus obras (Weber, 1963: 389-391; Teyssier, 1959: 249-250); en todo caso, se irán alejando progresivamente del personaje real y lo irán haciendo cada vez más literario y, por tanto, más uniforme y convencional; proceso que, en la literatura española, culmina con Lope de Rueda (Baranda, 1989: 313). Uno de estos rasgos, la abundancia de portuguesismos lingüísticos, se debe a tres motivos: en primer lugar, a la imitación que los literatos hacen de la realidad: los esclavos procedían de Portugal y de sus factorías africanas donde la lengua de contacto era una especie de criollo -sabir- de base portuguesa; en segundo lugar, a la influencia en nuestras letras de la tradición literaria que se inaugura en el país vecino con los textos de Silveira y Mota (Weber, 1963: 388); y, en tercer lugar a que el lenguaje de los portugueses era también un motivo de burla que aumentaría el potencial cómico de estos personajes.

En el caso de Breve, asistimos a una fiesta para celebrar la boda de la infanta doña Juana (hija de Juan II) con Enrique IV de Castilla. Se celebra un gran banquete y, entre los espectáculos programados, hay una representación en la que un actor disfrazado de rey de Guinea le presenta sus respetos a la princesa y se le ofrece para ejecutar un baile que, como aparece en el título que precede al texto, es el llamado "morisca retorta". El baile, según nos cuenta Garcia de Resende en Vida e feitos del rei D. Joâo, fue todo un éxito:

\begin{abstract}
"venían tres gigantes espantosos que parecían vivos, de más de cuarenta palmos cada uno, con ricos vestidos, todos pintados de oro que parecía cosa muy rica, y con ellos una muy grande y rica morisca retorta en que venían doscientos hombres teñidos de negro muy grandes bailarines, todos llenos de gruesas manillas por los brazos y piernas doradas que parecían de oro y llenos de cascabeles dorados y muy bien concertados, cosa muy bien hecha y de mucho trabajo por ser tantos, en que se gastó mucha seda y oro, y hacían tamaño ruido con los muchos cascabeles que traían que no se oían con ellos" (Resende, 1545: 74c-75c) ${ }^{5}$.
\end{abstract}

Para que el ofrecimiento que le hace a la princesa esté en consonancia con el exotismo de la representación, el actor que interpreta al rey de Guinea tiene que hablar como lo hacen los negros que por estos años llegan en gran número a Lisboa. Y esto es lo que intenta reproducir Silveira en su texto. A pesar del efecto cómico que sin duda provocaría el que un rey negro se expresara de manera tan extraña y se brindara a bailar delante de la corte, el personaje todavía no tiene tan marcado el carácter bufonesco que tendrá en obras posteriores (de hecho, se expresa en versos de arte mayor, los cuales se utilizan en esta época para composiciones de tono grave e inspiración elevada (Weber, 1963: 386-387), y su autenticidad como rey no se discute $)^{6}$. Nos atreveríamos a interpretar la escena como una exhibición ante la corte del poderío que Portugal, por estas fechas, está alcanzando gracias a sus conquistas africanas: se trata de un rey negro que presta vasallaje al rey de Portugal ("porque sempre nós servir vosso pai") y felicita a la princesa por sus esponsales.

\footnotetext{
${ }^{5}$ Traducción nuestra.

${ }^{6}$ Este carácter no cómico aún del personaje negro lo encontramos en dos obras tempranas: unas coplas atribuidas a Rodrigo de Reinosa en las que una señora solicita los servicios amorosos de un esclavo negro (comienzo de un mito erótico) y la Comedia Pródiga (1554) de Luis de Miranda, en la que el negro aparece como aliado de su señor (Baranda, 1989: 314).
} 
En Clérigo, el protagonista se lamenta de la pérdida de una pipa de vino que se le ha derramado. Culpa de su desgracia a la pipa, a los materiales de que estaba construida, al tonelero y, finalmente, a su esclava negra. Es ésta la única que puede responder a la acusación; se declara inocente y, ante la insistencia del clérigo, lo amenaza con desvelar secretos probablemente pecaminosos. El clérigo la toma en serio, reflexiona y opta por la resignación cristiana ante tan gran pérdida. No obstante, busca el consuelo en su amigo Álvaro Lopes, con quien comparte la forzada abstinencia del vino, y en las autoridades eclesiásticas y civiles que son los únicos personajes capaces de apreciar en su justa medida el valor de la pérdida: el vicario, el almojarife y el juez de los huérfanos. En este caso, la comicidad del personaje de la negra radica más en el hecho de ser la barragana del clérigo ("la Negra queda con vos, / con ella os confortaréis", le consuela el juez de los huérfanos) que en su lenguaje mismo (al que no se le niega, por supuesto, su valor bufonesco).

A pesar de no tener tan marcado carácter burlesco como los que aparecerán más adelante, estos dos primeros casos de negros con su modo de expresión peculiar dan origen a un tipo de personaje que se sumará a otros pertenecientes a la tradición cortesana y que también hacían uso de una lengua deformada con fines satíricos o cómicos: el pastor sayagués, el vizcaíno, el criado o el alfayate; personajes que representan la nota discordante en el seno de un conjunto de composiciones refinadas que se destinan a la corte. Veres D'Ocón (1950: 195-196) explica la aparición de estos personajes y de su forma peculiar de expresarse desde la perspectiva del Renacimiento: supondrían el ejemplo de lo erróneo, lo inelegante, lo rudo, frente a la armonía, el refinamiento y la sencillez representada por los personajes "serios". De ahí su ridiculización, pues se trata de ejemplos negativos: son errores, discordancias que provocan la risa entre los receptores acostumbrados a oír en las obras literarias el portugués o el castellano más exquisito, el que sirve de modelo de perfección.

Esta poesía cortesana que, a veces, está muy próxima a la dramática, como puede comprobarse en Clérigo, dará lugar a un teatro también cortesano que heredará temas y personajes y cuyo máximo ejemplo será el de Gil Vicente.

Estamos, pues, ante el comienzo de un tópico, pero un tópico fundado en la observación de la realidad ya que las primeras manifestaciones del hablar guineo intentan reproducir la manera de expresarse de los africanos procedentes de las factorías portuguesas. De ahí que muchos dialectólogos basen sus estudios sobre la lengua bozal en las manifestaciones lingüísticas de los negros que se recogen en textos literarios como los que aquí traducimos ${ }^{7}$. Dice Teyssier (1959:248-249) que si hacemos una comparación entre los rasgos lingüísticos que encontramos en la lengua de negro de las obras vicentinas y de los criollos portugueses africanos, los elementos comunes son numerosos, prueba evidente de que en la lengua de negro literaria (al menos, en sus comienzos, antes de convertirse en un estereotipo cuyos rasgos se repetirán de manera automática en obras posteriores) hay más imitación que invención.

Los rasgos lingüísticos más destacables en estos dos primeros ejemplos de la lengua afroportuguesa se hallan dentro de los niveles morfosintáctico y fonético: los personajes negros hacen uso de una sintaxis y una morfología esenciales y reducen la fonética a lo mínimo para ser entendidos, como es normal en hablantes que comienzan a manejar una

\footnotetext{
${ }^{7}$ Por ejemplo, el de Germán de Granda (1978).
} 
lengua extranjera o en niños que aprenden la propia. Prueba de ello es que, en las notas que tomó (sin ánimo de ridiculizar) el explorador Manuel Iradier en sus viajes a la colonia española de Guinea a fines del siglo XIX, aparecen reproducidos algunos testimonios orales de guineanos que hablaban español y que cometían errores ${ }^{8}$ que ya se habían recogido siglos atrás en la literaria lengua de negro: errores de concordancia de género ("todos las gentes" -p. 77-; "cosa malo" -p. 110) y de número ("el hombre blanco ... es [es]pañole" -p. 85-); elipsis de partículas de enlace ("dise no puere llegar" -p. 137-) o del artículo ("ha estao junto con pueblo" -p. 137-); confusión en el uso de las preposiciones ("lo mismo con [por "de"] día que con noche" -p. 130-); uso de la $3^{\mathrm{a}}$ pers. del sing. por la $1^{\mathrm{a}}$ y del pronombre personal objeto "mí" por el pronombre personal sujeto "yo" ("mí piensa en el tiempo" -p. 137-); construcción incorrecta de participio por analogía ("morío" -p. 137-); aféresis ("pañole" -p. 85-); debilidad de consonante final ("gente(s)","mira(r)" -p. 137-); confusión de líquidas r/l ("señol" -p. 137-); pérdida de -d- intervocálica ("dormío", "cuñao" -p. 137-) o conversión en -r- ("toro" por "todos", "puere" por "puede" -p. 137-); seseo ("hase", "dise" p. 137-)... Asimismo, en una História da igreja no Brasil, se dice que la lengua que se usaba para la catequesis de los negros era un portugués primario e infantil (Cunha-Henckel, 1993:56), parecido, suponemos, al que les serviría para comunicarse entre ellos o con los blancos.

En dialectología, a las variedades lingüísticas sumamente básicas que surgen de la necesidad de comunicación de dos colectivos que no comparten la misma lengua, se le denomina pidgin. Así lo define John M. Lipski (Perl, 1998: 295): "un lenguaje de contacto surgido por razones de urgencia en medio de grupos de personas que no comparten una lengua mutuamente conocida. El pidgin es una variedad sumamente reducida de una lengua natural". Según Germán de Granda (1978: 219, 228), este pidgin o, como él lo llama, "criollo de base portuguesa" lo traían ya los negros desde sus tierras africanas, donde lo habían aprendido gracias al contacto con los portugueses y a que era el único código de comunicación entre personas de lenguas maternas distintas. Le sirve para basar su afirmación (entre otros argumentos) lo que expone el sacerdote jesuita Alonso de Sandoval (1987: 140) en su Tractatus de instauranda aethiopum salute (1627):

"Y los que llamamos criollos y naturales de S. Thome, con la comunicación que con tan barbaras y reconditas naciones an tenido el tiempo que han recidido en $\mathrm{S}$. Thome las entienden casi todas con un genero de lenguage muy corrupto y revesado de la Portuguesa, que llaman lengua de S. Thome; al modo que agora nosotros entendemos y hablamos con todo genero de negros y naciones, con nuestra lengua Española corrupta, como comunmente la hablan todos los negros."

Una lingua franca parecida ya se había experimentado en la cuenca mediterránea durante la Edad Media, concretamente a partir de las Cruzadas y como consecuencia de las necesidades comunicativas entre sus participantes de distinto origen. Era lo que se denominaba sabir, cuyas primeras documentaciones se registran en los años 1284, 1304 y 1353 (Álvarez Nazario, 1974: 107). También Cervantes habla de una lengua franca o pidgin en el Mediterráneo:

\footnotetext{
${ }^{8}$ En una ocasión,el explorador llega a decir de unos negros que le acompañaban en sus expediciones que "hablan con mucha animación en un español que indignaría al príncipe de los ingenios" (Iradier, 2000: 111).
} 


\begin{abstract}
"la primera persona con quien encontré fue con su padre, el cual me dijo en lengua que en toda la Berbería, y aun en Costantinopla, se halla entre cautivos y moros, que ni es morisca, ni castellana, ni de otra nación alguna, sino una mezcla de todas las lenguas, con la cual todos nos entendemos" (Ariza, 1992: 51).
\end{abstract}

Algunos investigadores piensan que el pidgin afroportugués pudo haber recibido la influencia del sabir, ya que comparte con él gran número de rasgos: omisión del artículo, invariabilidad del adjetivo, simplificación de la conjugación verbal y del paradigma de los pronombres, etc. (Álvarez Nazario, 1974: 107).

Los fenómenos característicos de los textos que aquí presentamos, en el nivel morfosintáctico, son los siguientes (señalamos con $\mathrm{Cl}$. el texto de Clérigo y con $\mathrm{Br}$. el de Breve):

- Uso del pronombre personal objeto "mim" en vez del pronombre personal sujeto "eu": "mim também falar mourinho" (Cl., v. 59); alguna vez incluso con preposición: "A mim nunca mim / entornar" (Cl., vs. 41-42), "A mim rei de negro estar Serra Lioa" (Br., v.1). También puede aparecer el adjetivo posesivo con esta función: "e logo meu negro senhora balhar" (Br., v. 16) aunque se podría interpretar este caso como una impersonalización: "meu negro" > "o negro" > "eu".

- Uso del infinitivo con todos los valores de la conjugación: $1^{a}$ p. s. Pres. ind.: "A mim (...) estar" (Br., v. 1); $3^{\text {a }}$ p. s. Pres. ind.: "Aquí'star juiz no fora" (Cl., v. 57); $1^{\text {a }}$ p. pl. Pres. ind.: "viver nós" (Br., v. 2); $2^{\mathrm{a}}$ p. pl. Pres. ind.: "vós beber" (Cl., v. 51); $1^{\mathrm{a}}$ p. s. Pret ${ }^{0}$ perf. ind.: "mim andar augoá jardim" (Cl., v. 43); $3^{\mathrm{a}}$ p. s. Pret $^{\mathrm{o}}$ perf. ind.: "lodar caitbela" (Br., v. 3); $2^{\mathrm{a}}$ p. pl. Pres. imper.: "Bradar com almexerico" (Cl., v. 48).

- Uso de la $3^{\mathrm{a}}$ p. s. por la $1^{\mathrm{a}}$ p. s.: "a mim logo vai té lá" (Cl., v. 58); o por la $2^{\mathrm{a}}$ p. pl.: "ver vós como vai" (Br., v.5).

- Uso de "estar" por "ser": "A mim rei de negro estar Serra Lioa" (Br., v. 1); "folgar muito negro estar vós rainha" (Br., v. 8).

- Elipsis verbal: "mim nam medo no toucinho" (Cl., v. 61); "longe muito terra onde viver nós" (Br., v. 2); "aqueste gente meu taibo" (Br., v. 9).

- Elipsis del artículo: "longe muito (a) terra" (Br., v. 2); "folgar muito (os) negro(s)" (Br., v. 8); "Aquí'star (o) juiz no fora" (Cl., v. 57); también del adjetivo indefinido: "lodar (uma) caitbela" (Br., v. 3).

- Elipsis de partículas de enlace: preposiciones: "(na) terra nossa" (Br., v. 9); "mim andar (a) augoá jardim" (Cl., v. 43); o conjunciones (preferencia por la yuxtaposición, en vez de la coordinación o la subordinación): "Bradar com almexerico / Álvaro Lopo também" (Cl. vs. 48-49); "sempre nós servir vosso pai / folgar muito negro estar vós rainha" (Br., vs. 7-8); "vós logo todos chamar / vós beber / vós pipo nunca tapar / vós a mim quer o pingar / mim morrer" (Cl., vs. 5054); "Aquí'star juiz no fora / a mim logo vai té lá" (Cl., vs. 57-58).

- Errores de concordancia: de género: "molher meu" (Br., v. 6); "aqueste gente" (Br., v. 9); de número: "negro(s)" (Br., vs. 1, 8).

En cuanto al nivel fonético, apreciamos los siguientes fenómenos: 
- Debilidad de consonantes finales: "augoá(r)" (Cl., v. 43); "té(r)" (Cl., v. 55); "quer(er)" (Br., v. 13); "negro(s)" (Br., vs. 1, 8); "Lopo" por "Lopes" (Cl., v. 49). - Aféresis: "(a)té" (Cl., v. 55); "(e)star" (Cl., v. 57); "(a)sinha" (Br., v 6); "(a)qui" (Br., v. 11).

- Confusión del timbre de las vocales: tónicas: "sar" por "ser" (Cl., v. 44); o átonas: "pipo" por "pipa" (Cl., v. 52); "Lopo" por "Lope(s)" (Cl., v. 49); "sacrivâo" por "escrivâo" (con metátesis inicial) (Cl., v. 60).

- Reducción de un hiato: "Des" por "Deos" (Br., v. 15).

- Juegos de palabras debidos a confusión de varias lexías: "almexerico" (Cl., v.48) es el resultado de mezclar "almoxarife" y "mexerico" (ver traducción); "mourinho" ("morito") (Cl., v. 59) se utiliza en vez de "meirinho" ("merino"); o al mal aprendizaje: "caitbela" por "carabela" (Br., v.3), "muao" por "muitas" (Br., v. 4; a pesar de haber usado la palabra correctamente en el verso anterior: "muito").

Todos estos rasgos los podemos encontrar en los ejemplos de lengua de negro vicentina.También Reinosa, al imitar a Silveira, utiliza una estrofa de arte mayor, deforma el lenguaje como lo haría un negro y lo inunda de lusismos o de palabras aportuguesadas ${ }^{9}$. La diferencia está en que en las obras de Gil Vicente el número de fenómenos es más numeroso que en las de Silveira y Mota y, gracias a su uso continuado en las distintas piezas teatrales, se pueden sistematizar para convertirlos en el modelo que habrán de seguir tanto los autores portugueses como los españoles. Como ya se ha dicho, estaríamos ante lo que Granda (1978: 217) llama "primer momento fundamentalmente imitador y reproductor de una realidad lingüística dada", que dará paso, más tarde, a "una segunda fase en la que esta realidad de habla se estiliza, deforma y estereotipa, encajándose dentro de una tradición literaria determinada cada vez más rígida y menos vital". Otra diferencia (al menos de grado) radica en el uso completamente humorístico que hacen Reinosa (en sus dos composiciones claramente atribuidas) y Vicente de esta variedad tanto en la forma como en el contenido: los negros son estúpidos y tienen pretensiones absurdas,como convertirse en blanco (Fragua de amor -1524-) o ser amante de una dama (Nao de amores -1527-); o es un pícaro que engaña a un campesino palurdo (otro personaje tipo) y que, en sus intervenciones, introduce unos rezos totalmente deformados que provocarían la hilaridad de los espectadores (Clérigo de Beira -1529?/1530?-); o, por último, es un personaje masculino blanco que se disfraza de negra sirvienta e imita su lenguaje (Floresta de engaños -1536-). En cambio, en Breve, como hemos visto, la intención humorística no está tan marcada y en Clérigo la negra comparte rasgos bufos con los demás protagonistas, o sea, es un personaje tan cómico como los otros; pero, además, se permite la licencia de amenazar a su amo con denunciarlo a la autoridad y éste responde disculpándola por temor a la deshonra que supondría la difusión de sus relaciones íntimas y a la pérdida de las mismas; o sea, aparte de su ridiculez de farsa, la negra tiene cierta autoridad sobre su amo que, por lo que le conviene, la toma en serio.

\footnotetext{
${ }_{9}$ Weber (1963: 387). Veamos un breve fragmento sacado de "Comiençan unas coplas a los negros...": habla la negra Comba: "A mi llamar Comba, de terra Guinea / y en la mi terra comer buen cangrejo, / y allá en Gelofe, do tu terra fea / comer con gran hambre carauaju vejo, / cabeça de can, lagartu vermejo, / pudo tu andar muy muyto fambrento, / don puto negro carauayento." José Manuel Cabrales Arteaga (2000).
} 
Una coincidencia entre los textos afroportugueses vicentinos y los que aquí presentamos es que el léxico es completamente portugués (o español en el caso de Floresta de engaños) a diferencia de textos posteriores (sobre todo a partir del s. XVII), en los que aparecerán afronegrismos o bien palabras que imitan su sonoridad según los oídos europeos. Este hecho, por supuesto, no impide que, en los niveles fonético y morfosintáctico, los modelos sean fijados a partir de Gil Vicente. Por su parte, Reinosa hará uso de abundantes portuguesismos en sus textos por los motivos ya antes aludidos: imitación de la realidad lingüística de los negros castellanos (que hablaban una especie de pidgin afroportugués), influencia de los textos portugueses aquí traducidos y burla de la lengua lusitana.

La lengua de negro se convertirá, a partir del uso que de ella hagan Gil Vicente, Rodrigo de Reinosa y sus seguidores, en un rasgo más de humillación y desprecio del personaje africano en su papel de gracioso. Es lo más característico de estos personajes y lo que los identificará principalmente en una gran parte de los casos en que suban a escena o intervengan en obras de cualquier género literario. Aunque habrá excepciones. Desde el mismo siglo XVI (e incluso antes: Ejemplo XXXII de El conde Lucanor), nos encontraremos con negros ladinos que se expresan igual que los blancos (v.gr. el Lazarillo de Tormes, la Comedia Trofea de Torres Naharro y, posteriormente, comedias de negros dignificados -santos, sabios o soldados valerosos- a los que, como es lógico, no les convenía el aspecto burlesco del habla guineo -Álvarez Nazario, 1974: 113-114-). La lengua de negro será un elemento más que confirme la idea que de los negros se tiene: son inferiores física e intelectualmente a los blancos y están más cerca de los animales que de los humanos; en cuatro ocasiones, el clérigo utiliza con su esclava el insulto más frecuente para los negros (aunque también para moros y judíos):"perra"-Cl., vs. 37, 47, 55 y 68- . De hecho, todavía en el siglo XIX, nos cuenta Alfredo Margarido (1992: 63) que, en los círculos intelectuales portugueses, no se consideraba al africano como perteneciente a la especie humana ${ }^{10}$.

\section{C) LA IMAGEN DEL NEGRO}

La imagen del negro en el Portugal del siglo XIV y principios del XV es doble. Por un lado, tal como se hereda de los estereotipos medievales anteriores, es negativa, ya que se asocia el color negro con el demonio y el pecado: "Egipto y Etiopía son alegóricamente consideradas tierras de reserva del pecado, en el marco de una imagen estable del Occidente cristiano en el que la negritud es el signo del mal" (Silva Horta, 1991: 47) ${ }^{11}$. Por el otro, es

\footnotetext{
${ }^{10}$ Recordemos, asimismo, que hasta 1991 se estuvo exhibiendo en un museo de Banyoles (Gerona) un negro disecado como parte de una colección de historia natural; hasta esa fecha, nadie se había planteado la crueldad inhumana del hecho y hubo que luchar contra la oposición del pueblo para que, en 2000, fuera enterrado en Botsuana (cuyo gobierno lo reclamó) y así evitar una posible crisis internacional. En este orden de cosas, el 29 de abril de 2002, el Museo del Hombre de París entregó a Suráfrica la Venus hotentote, el molde de una indígena surafricana confeccionado a partir del esqueleto y partes del cerebro y genitales de la misma. Se trata de una historia que, por lo macabra e inhumana, ilustra perfectamente lo que aquí se expone: la mujer fue llevada a Europa en 1810 y exhibida desnuda, en Londres y París, como una curiosidad. Tras ser obligada a prostituirse y morir alcoholizada, fue diseccionada y convertida en la famosa Venus hotentote (El país, 30/IV/02).

${ }^{11}$ La identificación negro=diablo también la encontramos en la literatura castellana; por ejemplo, en unas coplas de Pedro de Cartagena escritas en la época de los Reyes Católicos: "alas verjas de vn corral / vi vn angel y vn diablo" [la dama con su criada negra] (Russell, 1978: 402, nota 2).
} 
relativamente positiva: frente a los judíos y los musulmanes (auténticos enemigos de la fe cristiana), los negros se engloban dentro del grupo de los gentiles-idólatras que no suponen un peligro para la cristiandad. A pesar de que haya por estas fechas pueblos mandingas islamizados que son objeto de esclavización por parte de los portugueses y a pesar de que como refiere el padre Sandoval (1987: 160) al hablar de los cafres "atheistas" del reino de Sofala (Mozambique)- son con los moros que allí habitan "casi una misma cosa, assi en la color negra, como en las costumbres y conversación", se les considera como cristianos potenciales que no lo son aún debido a su ignorancia. Viven en una inocencia infantil cercana a la estupidez o la bestialidad de los animales, la inocencia de los primeros tiempos, de la Edad de Oro (Silva Horta, 1991: 53-62) ${ }^{12}$. Esta idea todavía la encontraremos reflejada, alegóricamente, en un auto sacramental de Lope de Vega fechado entre 1621 y 1635: La siega. Aquí, la Envidia y la Soberbia han sembrado en el trigo del Señor, por descuido de Ignorancia, unas malas hierbas: la Idolatría (representada por un negro), el Hebraísmo, la Herejía y la Secta. Frente a las otras malas hierbas, el negro "pronto se muestra dispuesto a abjurar de su equivocado culto al sol y se ofrece como carbón para quemar a los infieles" (Weber, 1970: 358). Esta visión es la que permitió que, por una parte, se justificara espiritualmente la trata (había que acercarles la luz de Cristo ya que vivían aún en pecado original sin saberlo) y, por otra, que se considerara a los esclavos negros como niños o, mucho peor, como animales que no habían alcanzado la categoría de humanos por el estado salvaje en que habían vivido y que, por supuesto, carecían de honra o cualquier otra cualidad con que contaban los miembros legítimos de la sociedad en que se insertaban, fuera cristiana o islámica. Así lo observamos en el famoso Ejemplo XXXII de El conde Lucanor, "De lo que contesció a un rey con los burladores que fizieron el paño". El cuento, de origen árabe, transcurre en una corte a la que llegan unos embaucadores con un paño que tiene como característica excepcional el ser invisible para aquellos que no sean hijos legítimos, circunstancia que trae consigo resultados nefastos en el orden social (la deshonra), en el económico ("los moros no heredan cosa de su padre si non son verdaderamente sus fijos" -Don Juan Manuel, 1980: 213-), e incluso en el político (si el rey es bastardo tendrá que abdicar). Ante semejantes consecuencias, nadie (ni el camarero del rey, ni el alguacil, ni el privado, ni las "gentes", ni el propio rey) se atreve a aceptar ante los otros lo evidente: que el rey va desnudo. El cuento se resuelve cuando "un negro, que guardava el cavallo del rey e que non avía que pudiese perder" (1980: 216) descubre el engaño. O sea, el negro es un auténtico paria en la sociedad musulmana donde se desarrolla la historia y continúa siéndolo en la sociedad cristiana del XIV puesto que, en ningún momento, explica Patronio a su señor el estatus social del personaje. Se deduce del cuento que el negro era consciente y asumía como natural su falta de honra pues, según él mismo dice (todavía en perfecto castellano), "a mí non me enpeçe que me tengades por fijo de aquel padre que yo digo, nin de otro" (1980: 216); puede, pues, sin temor alguno, decir la verdad. Es, por un lado, la imagen del paria y, por otro, la de la inocencia beatífica de quien es incapaz de mentir y ser hipócrita; de hecho, en la versión de Andersen el negro será sustituido por un niño.

Del pecado original los salva, los libera, paradójicamente, la esclavitud. Esta teoría, junto con la de la justificación aristotélica del sometimiento servil de unos seres humanos a

\footnotetext{
${ }^{12}$ La composición de tema negro que se le atribuye a Reinosa reproduce el texto de una vieja canción infantil; esta asociación negro-niño refleja una de las actitudes españolas frente al subsahariano (Russell, 1978: 386-387).
} 
otros, necesitaban de propaganda y tal función la llevó a cabo, sobre todo, el teatro. En él, la imagen ridícula del negro, cuyos precedentes aquí presentamos, es caricaturesca y responde a la idea de que es lógico que unos seres tan estúpidos, infantiles y brutos estén esclavizados, pues no son personas como los blancos a pesar de que se les haya otorgado la gracia de bautizarlos. Así pues, la visión positiva que de los negros se tenía: eran considerados criaturas inocentes frente a los auténticos enemigos de la fe, musulmanes y judíos (a los que se expulsa de la Península al tiempo que llegan cada vez más subsaharianos), se vuelve contra ellos por la sencilla razón de que hay que justificar su estado de esclavitud. Inocente es el niño, pero también el animal y rasgos de uno y de otro tendrá el negro según convenga al amo y a la sociedad en que viva. Dicha imagen cumple, además, otra función: la de crear un estereotipo. Con ella se enseñaba al público a enfrentarse a una novedad que suponía una anomalía en el orden social. Si bien, como hemos dicho, antes de la Edad Moderna había habido negros en la península gracias al contacto con los musulmanes, la novedad estaba en que no habían sido tan numerosos como ahora empezaban a serlo.

El estereotipo nos salva de lo extraño, nos salva de la angustia de no saber cómo responder a lo que se escapa de nuestra concepción del mundo. Como dice Fra Molinero (1995: 52-53), "los negros cómicos del teatro español y portugués tenían una función definidora de las actitudes sociales hacia los negros en general". A este objetivo responde la caricatura cruel con la que serán presentados los negros graciosos durante más de cinco siglos y en la que cumplirá un papel esencial su forma de expresarse: desde el texto de Anrique da Mota hasta los doblajes de algunas películas estadounidenses en que los negros intervienen todavía como cándidos bufones que cantan, bailan y hacen reír con sus simplezas a los demás personajes y a los espectadores.

\section{D) NUESTRA EDICIÓN}

Los originales de los textos que vienen a continuación están sacados, el de Fernâo da Silveira, del Cancioneiro Geral de Garcia de Resende y el de Anrique da Mota, de Obras de Anrique da Mota (edición de Osório Mateus). En la traducción, hemos procurado adaptar el texto portugués, en la medida de lo posible, a un español que haga comprensible el sentido del original. En el caso de la lengua de negro objeto de nuestro estudio, hemos intentado la imitación (en concreto, en el caso de Clérigo), o sea, la traslación de la lengua de negro portuguesa a la lengua de negro española (una de cuyas características, no lo olvidemos, es la de la presencia de abundantes lusismos). Este atrevimiento ha dado lugar a una proliferación de notas a pie de página que son las que, en último término, explican el significado completo en cada caso. Confiamos en que las tres versiones de los textos (original, traducción y notas) se complementen y sirvan para su correcta comprensión.

\section{E) Los textos}

Fernão da Silveira: por breve

$$
\text { deũa mourisca ratorta que mandou fazer a senhora princesa, quando esposou }{ }^{13}
$$

[fala do rei de Guiné]

\footnotetext{
${ }^{13}$ La transcripción que utilizamos es de José Camões; la traducción y la puntuación están basadas en la traducción al portugués contemporáneo que hizo Paul Teyssier (1959: 228).
} 
A mim rei de negro estar Serra Lioa

longe muito terra onde viver nós

lodar caitbela tubao de Lisboa

falar muao novas calar pera vós. querer a mim logo ver vós como vai leixar molher meu partir muito sinha porque sempre nós servir vosso pai folgar muito negro estar vós rainha

aqueste gente meu taibo terra nossa nunca folgar andar sempre guerra nam saber qui que balhar terra vossa balhar que saber como nossa terra. se logo vós quer mandar a mim venha fazer que saber tomar que achar mandar fazer taibo lugar Des mantenha e logo meu negro senhora balhar.

\section{Fernão da Silveira: por breve ${ }^{14}$ de una morisca retorta ${ }^{15}$ que mandó hacer la señora princesa cuando se casó}

[Habla del rey de Guinea]

Yo soy el rey de los negros de Sierra Leona.

La tierra donde vivimos queda muy lejos.

Llegó una carabela "tubao"16 de Lisboa.

Dio muchas noticias de un casamiento vuestro.

Inmediatamente quise ver cómo erais.

Dejé a mi mujer, partí deprisa,

porque nosotros siempre servimos a vuestro padre

y los negros se alegran mucho de que seáis reina.

Esta gente es muy buena. En nuestra tierra nunca holgamos, siempre estamos en guerra.

No sé lo que bailaré aquí en vuestra tierra.

Bailaré lo que sé, como en nuestra tierra.

Por tanto, si queréis mandar que yo venga,

haré lo que sé, escogeré lo que crea mejor.

\footnotetext{
${ }^{14}$ En las fiestas y torneos, el breve era un escrito que los caballeros entregaban a las damas a cuya honra mantenían la justa. En este caso, el rey de Guinea, en señal de sumisión a la princesa, le ofrece el que aparece a continuación que servirá de letra para una morisca retorta. La expresión "por breve" significaría "a modo de breve".

${ }^{15}$ Tipo de danza. Su nombre y la aparición de arabismos como "taibo" son argumentos para probar la confusión que a veces se establece entre negros y árabes; confusión que se acrecienta con el hecho histórico de la islamización de algunos pueblos mandingas objeto de la trata portuguesa (C. Baranda, 1989: 319-322).

${ }^{16}$ Probablemente se refiera al corregidor Tibau, personaje real de la época (Teyssier, 1959: 228, 237); así, el sentido sería que "Tibau arribó a Sierra Leona en una carabela proveniente de Lisboa". Por otra parte, Juan González Núñez, en su libro Etiopía: hombres, lugares y mitos, cita un texto etíope de 1542 en el que se les llama a los portugueses "hijos de Tubal" (Reverte, 2001: 72). Si la palabra es la misma, podríamos tomarla como sinónima de "portugués" y el sentido del verso cambiaría a "Llegó una carabela portuguesa de Lisboa".
} 
Mandad hacer buen lugar, ¡Dios guarde!

y enseguida yo, negro, señora, bailaré.

D'Anrique da Mota a um Créligo sobre ũa pipa de vinho que se lhe foi polo chão, e lamentava-o desta maneira ${ }^{17}$ :

Ai ai ai ai que farei
ai que dores me cercaram
ai que novas me chegaram
ai de mim onde me irei?
que farei triste mesquinho
com paixão
tudo leva mau caminho
pois que vai todo meu vinho
pelo chão

ó vinho quem te perdera
primeiro que te comprara
oh quem nunca te provara
ou provando-te morrera.
oh quem nunca fora nado
neste mundo
pois vejo tan mal logrado
um tal bem tam estimado
tam profundo
ó meu bem tam escolhido
que farei em vossa ausência?
nam posso ter paciência
por vos ver assi perdido.
ó pipa tam mal fundada
desditosa
de fogo sejas queimada
por teres tam mal guardada
esta rosa
ó arcos por que suxastes
ó vímens de maldição
por que nam tivestes mão
assi como me ficastes?
ó mau vilão tenoeiro
desalmado
tu tens a culpa primeiro
pois levaste o meu dinheiro
mal levado
20

\footnotetext{
${ }^{17}$ En el texto original, hemos respetado los criterios de edición del profesor Osório Mateus (Mota, 1999): puntuación, mayúsculas, acotaciones, distribución del texto...; en la traducción, hemos optado por restituir la puntuación y las mayúsculas que hemos creído oportunas para la correcta comprensión de la obra.
} 
Fala com a sua Negra:

\begin{tabular}{|c|c|c|}
\hline Negra & $\begin{array}{l}\text { ó perra de Manicongo } \\
\text { tu entornaste este vinho } \\
\text { ?a posta de toucinho } \\
\text { t'hei de gastar nesse lombo. } \\
\text { A mim nunca nunca mim } \\
\text { entornar } \\
\text { mim andar augoá jardim } \\
\text { a mim nunca sar roim } \\
\text { por que bradar? }\end{array}$ & 45 \\
\hline $\begin{array}{l}\text { Clérigo } \\
\text { Negra }\end{array}$ & $\begin{array}{l}\text { Se nam fosse por alguém } \\
\text { Perra eu te certifico. } \\
\text { Bradar com almexerico } \\
\text { Álvaro Lopo também. } \\
\text { vós logo todos chamar } \\
\text { vós beber } \\
\text { vós pipo nunca tapar } \\
\text { vós a mim quer o pingar } \\
\text { mim morrer. }\end{array}$ & 50 \\
\hline $\begin{array}{l}\text { Clérigo } \\
\text { Negra }\end{array}$ & $\begin{array}{l}\text { Ora perra cal-te já } \\
\text { se nam matar-t'-ei agora. } \\
\text { Aquí'star juiz no fora } \\
\text { a mim logo vai té lá. } \\
\text { mim tambem falar mourinho } \\
\text { sacrivão } \\
\text { mim nam medo no toucinho } \\
\text { guardar nam ser mais que vinho } \\
\text { creligão. }\end{array}$ & 55 \\
\hline Clérigo & $\begin{array}{l}\text { Ora te dou ò diabo } \\
\text { rogo-te já que te cales } \\
\text { que bem m'abastam meus males } \\
\text { que me vem de cada cabo. } \\
\text { olhai a perra que diz } \\
\text { que fará } \\
\text { irá dizer ò juiz } \\
\text { o que fiz e que nam fiz } \\
\text { e crê-l'-á } \\
\text { e pois ela é tam roim } \\
\text { bem será que me perceba } \\
\text { dirá qu'é minha manceba } \\
\text { pera se vingar de mim. } \\
\text { entam em provas nam provas } \\
\text { gastarei } \\
\text { irão dar de mim más novas } \\
\text { e farão sobre mim trovas }\end{array}$ & 75 \\
\hline
\end{tabular}


que farei?

o siso será calar

pera nam buscar desculpa

pois a Negra nam tem culpa

pera que lha quero dar?

eu sam aquí o culpado

e outrem nam

eu sam o denificado

e eu sam o magoado

eu o sam

90

que negra entrada de Março se todo vai por est'arte

e as terçãs doutra parte

hão-me de dar um camarço

ó vós outros que passais

pelas vinhas

respondei assi vivais

se vistes dores igoais

co as minhas

Fim em vilancete:

pois nam tenho aquí parentes

saltem vós amici mei

chorareis como chorei

chorareis a minha pipa

chorareis o ano caro

chorareis o desemparo

do meu bem de Caparica.

e pois tanta dor me fica

saltem vós amici mei

chorareis como chorei

Fala com o Vigairo:

ó gordo padre vigairo

vós que sabeis que dor é

ajudai por vossa fé

a chorar este fadairo.

se perdera o breviairo

nem a capa que comprei

Responde o Vigairo: 
Ó irmão muito perdeste e segundo em mim sento nam tevera atrevimento de sofrer o que sofreste. é um tam grande mal este que com dó que de ti hei pera sempre chorarei.

Fala com Álvaro Lopes:

Ó Álvaro irmão amigo vê-lo jaz aquí no chão pois perdeste teu quinhão vem e chorarás comigo. certamente eu te digo que quando morreu el rei pardeos tanto nam chorei.

Reposta d'Álvaro Lopes:

Milhor me fora perder dez mil vezes meu ofício ou um grande benefício que tanta pena sofrer. pois nam temos que beber ó irmão onde m'irei pois que choras chorarei.

Fala com o Almoxarife:
Ó Almoxarife irmão levantemos esta pipa e veremos se the fica ainda algum nembro são. mas eu tenho tal paixão do triste que nam logrei que por sempre chorarei.

Responde o Almoxarife:

Pois que nam tem alma já pera qu'é a levantada? mas muito pior será que dizem que ficará esta casa violada. a confraria é danada ó irmão que te farei? se chorares chorarei. 
Fala com o Juiz dos órfãos:

Vós que tendes jurdiçam naqueles que nam tem pai vinde vinde aqui chorai que eu também órfão sam. e que vossa condiçam seja d'água como sei chorareis como chorei.

Reposta do Juiz dos órfãos:

Esforçai nam vos mateis

perto é daqui a Agosto

a Negra fíca convosco

com que vos confortareis.

do perdido nam cureis

nem chameis aquel del rei

e eu vos consolarei.

Fim da lamentação do Créligo:

Todo género honrado em que vertude consiste ajudai chorar o triste que jaz aquí entornado.

e pois eu por meu pecado pera tanto mal fiquei pera sempre chorarei.

De Anrique da Mota a un Clérigo sobre una pipa de vino que se le fue por el suelo, y lamentábalo de esta manera:

¡Ay, ay, ay, ay, qué haré!

¡Ay, qué dolores me cercaron!

¡Ay, qué nuevas me llegaron!

¡Ay de mí! ¿Adónde me iré?

¿Qué haré, triste, mezquino, con pasión ${ }^{18}$ ?

Todo lleva mal camino

pues que va todo mi vino

por el suelo.

¡Vino, quién te perdiera

antes de que te comprara!

\footnotetext{
${ }^{18}$ Gran disgusto, sufrimiento.
} 
¡Oh, quién nunca te probara

o probándote muriera!

¡Oh, quién nunca fuera nado ${ }^{19}$

en este mundo

pues veo tan mal logrado

un tal bien tan estimado,

tan profundo!

Mi bien, tan escogido,

¿qué haré en vuestra ausencia?

No puedo tener paciencia

por veros así perdido.

Pipa tan mal fundada ${ }^{20}$, desdichada.

De fuego seas quemada

por tener tan mal guardada

esta rosa.

Arcos ¿por qué ensanchasteis?

Mimbres de maldición

¿por qué no aguantasteis

así tal como estabais?

Mal villano tonelero,

Desalmado,

la culpa es tuya el primero

pues llevaste mi dinero

mal llevado.

Habla con su Negra:

Perra de Manicongo,

tú derramaste este vino.

La tajada de tocino

te he de gastar en el lomo ${ }^{21}$.

Negra: $\quad$ Mí nunca, nunca mí

derramar.

Mí andar aguar jardín.

A mí ${ }^{22}$ nunca ser ruin.

¿Por qué gritar?

Clérigo: Si no fuese por alguien,

Perra, yo te aseguro... ${ }^{23}$.

\footnotetext{
${ }^{19}$ Participio irregular antiguo de "nacer".

${ }^{20}$ Construida.

${ }^{21}$ El clérigo la amenaza con pringarla, esto es, echarle sobre las heridas de los azotes la pringue del tocino hirviendo. Era una forma habitual de castigo para los esclavos que encontramos, por ejemplo, en el Lazarillo de Tormes, donde el esclavo negro con el que la madre del protagonista mantenía relaciones es castigado por la justicia de ese modo: "Al triste de mi padre azotaron y pringaron" (1977: 66).

22 "A mí", "mí" o "me" son utilizados en la lengua de negro con valor de sujeto de primera persona del singular.
} 
Negra: Gritar al almejerico ${ }^{24}$,

a Álvaro Lopo también ${ }^{25}$

Vos siempre todos llamar, vos beber ${ }^{26}$,

vos pipo nunca tapar,

vos a mí querer el pringar.

Mí morir.

Clérigo: Ora, perra, cállate ya,

Negra: $\quad$ Aquí estar ${ }^{27}$ juiz no fora ${ }^{28}$.

A mí ya va hasta allá ${ }^{29}$.

Mí también hablar merino, notario ${ }^{30}$.

Mí no miedo del tocino.

¡Guardar no ser más que vino ${ }^{31}$, clerigón!

Clérigo: Ahora te doy al diablo, ruégote que te calles, que ya me bastan mis males que de todas partes llegan.

\footnotetext{
${ }^{23}$ El sentido del texto no está del todo claro. Parece que hay una amenaza por parte del clérigo que no termina de ser expuesta; por eso lo hemos interpretado como una reticencia. La proposición condicional podría ser una frase hecha o bien referirse a alguien que desconocemos.

${ }^{24}$ La negra mezcla dos palabras portuguesas: almoxarife (recaudador de las rentas y derechos del rey, tesorero; en español "almojarife") y mexerico (enredo, intriga). En español no existe la segunda palabra aunque sí la raíz sobre la que ésta se forma: "mecer", con el mismo significado que en portugués: "menear y mover un líquido de una parte a otra para que se mezcle o incorpore". Puesto que, de todos modos, la comicidad del vulgarismo portugués se pierde al intentar traducirlo al español, hemos optado por inventar una palabra que, al menos, conserve la rima de la composición y no pierda totalmente la similitud con una de las palabras sobre las que se forma.

${ }^{25}$ Leite de Vasconcelos (1933: 244) atribuye al clérigo estos dos versos últimos y da una posible interpretación de lo que expresa el personaje: "Si no fuese por querer acusar a alguien (pues tú no eres nadie), yo te aseguro, perra, que enredaría también en esto (en el daño que me causaste) a Álvaro Lopo, de connivencia contigo". Según esta lectura, Álvaro Lopo no es el mismo personaje que aparece más tarde con el nombre de Álvaro Lopes (vv. 124152). Sin embargo, la ausencia de conjunción copulativa entre los dos versos y de artículo delante del sustantivo almexerico, y la confusión de esta misma palabra nos hace pensar que es la negra y no el clérigo quien habla; por otro lado, es más probable que el personaje que nombra la negra sea el amigo del clérigo que aparece más adelante que otro con nombre, casualmente, casi idéntico.

${ }^{26}$ Entiéndase "con ellos".

${ }^{27}$ Hay.

${ }^{28}$ Juiz no fora es una alteración de juiz de fora: antiguo magistrado que corresponde al actual juez de Derecho.

${ }^{29}$ A mim logo vai té lá se presta a dos interpretaciones según consideremos té como adverbio: até, o como verbo: ter. De todos modos, las expresiones son muy parecidas: "Voy allí inmediatamente".

30 "Hablaré también con el merino ('juez que se ponía por el rey en un territorio en donde tenía jurisdicción amplia' según el D.R.A.E.) y con el notario" (en el texto: sacrivão por escrivão).

31 "Guardaos de que no sea más que vino". La negra amenaza a su amo con revelar a la justicia cosas que el clérigo esconde. Puede que se refiera a las alusiones que el propio clérigo hace más adelante (vv. 64-80). Esta interpretación de Teyssier no coincide con la de Leite de Vasconcelos quien propone la siguiente versión: el vino de clérigo no sirve de nada ¿para qué guardarlo? Esto es: no se perdió nada al derramarlo.
} 
Ved lo que la perra dice

que hará:

irá a decir al juez

lo que hice y que no hice

y la creerá.

Y pues ella es tan ruin, bien será que me aperciba; dirá que ella es mi querida para vengarse de mí.

Entonces, en pruebas no pruebas ${ }^{32}$ gastaré;

darán de mí malas nuevas y harán sobre mí trovas.

¿Qué haré?

Prudencia será callar para no buscar disculpa: pues la Negra no ha culpa, ¿para qué se la quiero dar? Yo soy aquí el culpado y otro no, yo soy el damnificado y yo soy el disgustado, yo lo soy.

¡Qué negra entrada de marzo

si todo sigue esta suerte y tercianas, por su parte, me van a hacer desgraciado! $!^{33}$ Vosotros que pasáis por las viñas, responded, así viváis, si visteis dolores iguales a los míos.

Fin en villancico:

Pues no tengo aquí parientes, venid vos, amici mei; lloraréis como lloré.

Lloraréis por mi pipa,

\footnotetext{
${ }^{32}$ Se trata de una metáfora de la burocracia judicial. Ante la amenaza de la negra de ir a quejarse, el clérigo refiere la lentitud de los procesos por motivos de cosas que van y que vienen.

${ }^{33}$ El clérigo, probablemente, curaba las fuertes fiebres tercianas con vino. El original portugués dice hão-me de dar un camarço; esta última palabra significa desgracia, infortunio, enfermedad, achaque. La traducción más literaria sería: "y las tercianas, por otra parte,/ me van a provocar una desgracia".
} 
lloraréis el año caro

lloraréis el desamparo

de mi bien de Caparica ${ }^{34}$.

Y pues tal dolor me queda, venid vos, amici mei,

lloraréis como lloré.

Habla con el Vicario:

Gordo padre vicario,

vos que sabéis qué dolor es ayudad por vuestra fe a llorar este mal hado.

Si yo perdiera el breviario o la capa que compré, no llorara lo que lloré.

Responde el Vicario:

Hermano, mucho perdiste y, según en mí yo siento, no tuviera atrevimiento de sufrir lo que sufriste. Es un tan grande mal este que el dolor que de ti he para siempre lloraré.

Habla con Álvaro Lopes:

Álvaro, hermano, amigo, ve cómo yace en el suelo; pues perdiste tu quiñón ${ }^{35}$, ven y llorarás conmigo. Ciertamente yo te digo que, cuando murió el rey, ipardiez! tanto no lloré.

Respuesta de Álvaro Lopes:

Más me valiera perder diez mil veces mi oficio o un grande beneficio que tanta pena sufrir. Pues no tenemos qué beber, hermano, adónde iré.

\footnotetext{
${ }^{34}$ Zona productora de vino situada al sur de Lisboa.

${ }^{35}$ Parte, porción.
} 
Pues que lloras, lloraré.

Habla con el Almojarife:
Almojarife, hermano, levantemos esta pipa y veremos si le queda aún algún miembro sano. Mas yo tengo tal disgusto por el triste ${ }^{36}$ que no logré, que por siempre lloraré.

Responde el Almojarife:

Pues que no tiene alma ya, ¿para qué la levantada? Mas, mucho peor será que digan que quedará esta casa profanada ${ }^{37}$. La cofradía ${ }^{38}$ es dañada, hermano ¿qué te haré? Si tú lloras, lloraré.

Habla con el Juez de los huérfanos:

Vos que habéis jurisdicción sobre quien no tiene padre, venid aquí y lloraréis que también huérfano soy. Y que vuestra condición sea de agua como sé ${ }^{39}$, lloraréis como lloré.

Respuesta del Juez de los huérfanos:

Esforzaos, no os matéis, cerca de aquí está agosto, la Negra queda con vos, con ella os confortaréis. De lo perdido no curéis ni llaméis "aquí del rey"

\footnotetext{
${ }^{36}$ Se refiere al vino.

${ }^{37}$ Se establece un paralelismo metafórico entre la pipa y un cuerpo: si el cuerpo (la pipa) yace muerto, sin alma (con su contenido derramado), para qué cometer el pecado de profanar un cadáver.

${ }^{38}$ Congregación.

${ }^{39}$ Y ya que vuestra situación / es de agua como sé (porque también os habéis quedado sin vino).
} 
y yo os consolaré.

Fin de la lamentación del Clérigo:

$$
\begin{aligned}
& \text { Todo género honrado } \\
& \text { en que la virtud consiste: } \\
& \text { ayudad a llorar por el triste } \\
& \text { que yace aquí derramado. } \\
& \text { Y pues yo, por mi pecado, } \\
& \text { para tanto mal quedé, } \\
& \text { para siempre lloraré. }
\end{aligned}
$$

\section{REFERENCIAS BIBLIOGRÁFICAS}

ALMEIDA, J. e SAMPAIO, A.: Dicionário da língua portuguesa, Porto, Porto Editor, 1989.

ÁlVAREZ NAZARIO, M.: El elemento afronegroide en el español de Puerto Rico, San Juan de Puerto Rico, Instituto de cultura puertorriqueña, 1974.

ANÓNIMO: Lazarillo de Tormes, Madrid, Editora Nacional, 1977.

ARIZA, M.: "La lengua de las minorías en el Siglo de Oro", en Problemas y métodos en el análisis de textos. In memoriam Antonio Aranda, Sevilla, Universidad, 1992.

BARANDA LETURIO, C.: "Las hablas de negros. Orígenes de un personaje literario" en Revista de Filología Española, LXIX (1989), pp. 311-333.

CABRALES ARTEAGA, J. M.: "Rodrigo de Reinosa. Un poeta del pueblo" en Cuadernos de Campoo, 9 de octubre de 2000, <http: // personales.mundivia.es / flipi / Cuadernos_3/rodrigo_de_reinosa.htm $>$.

COSSÍO, J. M. de: Estudios sobre escritores montañeses, Santander, Diputación Provincial, 1973.

CUNHA-HENCKEL, R. A.: "Empréstimos lexicais bantos no português do Brasil: ponto provisório da situação num projeto de doutoramento" en Actas do $4^{\circ}$ Congresso da Associação internacional de lusitanistas, Lisboa, Lidel, 1993, pp. 55-62.

MOLINERO, B. Fra: La imagen de los negros en el teatro del Siglo de Oro, Madrid, Siglo XXI de España Editores, 1995.

GIESE, W.: "Notas sobre a fala dos negros em Lisboa no princípio do século XVI" en Revista Lusitana, XXX, n 1-4 (1932), pp. 251-257.

GRANDA, G. de: Estudios lingüísticos hispánicos, afrohispánicos y criollos, Madrid, Gredos, 1978.

DON JUAN MANUEL: El conde Lucanor, Madrid, Ed. Cátedra, 1980

IRADIER, M.: África, Barcelona, Mondadori, 2000.

LEITE DE VASCONCELOS, J.: "Língua de preto num texto de Henrique da Mota" en Revue Hispanique, $\mathrm{n}^{\circ} 81$ (1933), pp. 241-246.

MARGARIDO, A.: "Escritura e identidad" en Quimera, n 112-113-114 (1992), pp 60-68. 
MOTA, A. da: Obras, Lisboa, CNCDP, 1999 (edición de Osório Mateus).

PERL, M. y SCHWEGLER, A. (eds.): América negra: panorámica actual de los estudios lingüísticos sobre variedades hispanas, portuguesas y criollas, Madrid, Iberoamericana / Vervuert, 1998.

PHILIPS JR., W. D..: Historia de la esclavitud en España, Madrid, Ed. Playor, 1990.

RESENDE, G. de: Cancioneiro Geral, Almeirim e Lisboa, Herman de Campos, 1516 (transcripción de José Camões).

RESENDE, G. de: "Vida e Feitos d'el rei dom João Segundo" en Libro das Obras de Garcia de Resende que trata da vida e grandíssimas virtudes e bondades, magnânimo esforço, excelentes costumes e manhas e mui craros feitos do cristianíssimo, muito alto e muito poderoso príncipe el rei dom João o segundo deste nome, e dos reis de Portugal o trezeno, de gloriosa memória. Começado de seu nascimento e toda sua vida até à hora de sua morte. Com outras obras que adiante se seguem. Lisboa, Luís Rodrigues, 1545, folios 74c-75c (transcripción de José Camões).

REINOSA, R. de: Coplas, Madrid, Taurus, 1970.

REVERTE, J.: Dios, el diablo y la aventura, Barcelona, Plaza \& Janés, 2001,

RUSSELL, P. E.: "La «poesía negra» de Rodrigo de Reinosa" en Temas de La Celestina y otros estudios, Barcelona, Ariel, 1978.

SANDOVAL, A. de: Un tratado sobre la esclavitud, Madrid, Alianza Editorial, 1987 (edición de Enriqueta Vila).

SILVA HORTA, J. da: "A imagem do Africano pelos portugueses antes dos contactos" en L. de Albuquerque y otros: O confronto do olhar, Lisboa, Caminho, 1991

TEYSSIER, P.: La langue de Gil Vicente, París, Librairie C. Klincksieck, 1959.

VERES D'OCÓN, E.: "Juegos idiomáticos en las obras de Lope de Rueda" en Revista de Filología Española, T. XXXIV, 1976, pp. 195-227.

VICENTE, G.: As obras de Gil Vicente, Lisboa, Centro de Estudos de Teatro, Imprensa Nacional-Casa da Moeda, 2002 (edición de José Camões).

WEBER DE KURLAT, F.: "Sobre el negro como tipo cómico en el teatro español del siglo XVI" en Romance Philology, vol. XVII, nº 2, 1963, pp. 380-391.

WEBER DE KURLAT, F: "El tipo del negro en el teatro de Lope de Vega: tradición y creación" en Nueva Revista de Filología Hispánica, T. XIX, n² 2, 1970, pp. 337359.

ZIMMERMANN, K. (ed.): Lenguas criollas de base lexical española y portuguesa, Madrid, Iberoamericana / Vervuert, 1999. 
